\title{
Use of Color Doppler Ultrasound for the Diagnosis of Subarachnoid Hemorrhage in Asymptomatic Full-Term Neonate: A Case Report
}

\author{
Hélio A. Guimarães Filho ${ }^{1,2^{*}}$, Janett J. Liberalino ${ }^{1}$, Ana T. P. Mendonça ${ }^{1}$, Carlos V. S. B. Leite Filho ${ }^{1}$, \\ Leonardo F. Felipe ${ }^{1}$, Carlos F. Melo Júnior ${ }^{1,3}$ \\ ${ }^{1}$ CETRIM-Imaginology Training Center, João Pessoa, Brazil; ${ }^{2}$ Departament of Ultrasound, Frei Damião Maternity, João Pessoa, \\ Brazil; ${ }^{3}$ Department of Radiology, Federal University of Paraiba, João Pessoa, Brazil. \\ Email: ${ }^{*}$ helioagf@hotmail.com
}

Received December $17^{\text {th }}, 2011$; revised January $29^{\text {th }}, 2012$; accepted February $16^{\text {th }}, 2012$

\begin{abstract}
Cerebral hemorrhages are fairly common in full-term neonates with no history of traumatic birth, mostly limited, and with benign evolution. We report a case of a full-term neonate from vaginal birth with caput succedaneum in the right parietal area. The neonate underwent cranial ultrasonography and color Doppler which showed extra-axial blood effusion. Color Doppler showed vessels crossing the collection area, which allowed the diagnosis of subarachnoid hematoma.
\end{abstract}

Keywords: Cerebral Hemorrhage; Subarachnoid Hematoma; Cranial Ultrasound; Color Doppler

\section{Introduction}

Some risk factors to intracranial hemorrhage in full-term neonates have been identified, such as: fetal macrosomia, prolonged labor, use of obstetrical forceps or vacuum extraction [1]. These neonates usually have apnea, bradcardia or seizures after subdural, subarachnoid or intraparenchymal hemorrhages. On the other hand, intracranial hemorrhages in asymptomatic neonates may be common after vaginal birth, though reports on the use of color Doppler ultrasound are rare [1-3]. The present case report describes the use of ultrasound and the importance of color Doppler for the diagnosis of subarachnoid hemorrhage in a full-term neonate.

\section{Case Report}

F. A. C., 25 years old, was admitted to the maternity ward Frei Damião, João Pessoa-Brazil, in labor, on 09/26/2011. It was a prolonged labor (14 hours) with vaginal birth. No clinical signs of fetal distress were reported during labor. The neonate had 1 minute and 5 minutes Apgar scores of 7 and 10, respectively. Physical examination showed caput succedaneum in the posterior parietal area. In his sixth day of life, the neonate underwent cranial ultrasound (US) with color Doppler which showed the following: subgaleal hematoma in the posterior parietal area;

"Corresponding author. no presence of malformations or of parenchymal or intraventricular hemorrhages; blood effusion was seen in the intracranial right parietal area, adjacent to the subgaleal hematoma, measuring $6.0 \times 1.5 \times 4.9 \mathrm{~cm}$ (Figures 1 and 2). Color Doppler showed blood vessels crossing the hematoma area, confirming the subarachnoid hemorrhage (Figure 3). The neonate showed good health conditions and was neurologically normal, under exclusive breastfeeding. Watchful waiting and monitoring by means of US were recommended, and showed gradual reduction of the hematoma. After 20 days of life, the neonate underwent a cranial computed tomography scanning which showed the complete resolution of the hemorrhage. During all this time, the neonate remained asymptomatic.

\section{Discussion}

Intracranial hemorrhage in neonates is always a concerning event to physicians and family, mainly because of the fear of future neurological sequelae. Recent studies have showed conflicting results regarding the incidence of intracranial hemorrhages (subdural, subarachnoid, parenchymal and intraventricular) in asymptomatic neonates and with no history of traumatic birth $[1,4]$. In the study of Looney et al. a $26 \%$ rate of intracranial hemorrhage was found in 97 normal neonates with no traumatic birth [1]. Another study, however, found only 1 case $(0.2 \%)$ of intracranial hemorrhage in 493 asymptomatic term neonates were examined by ultrasound [4]. 


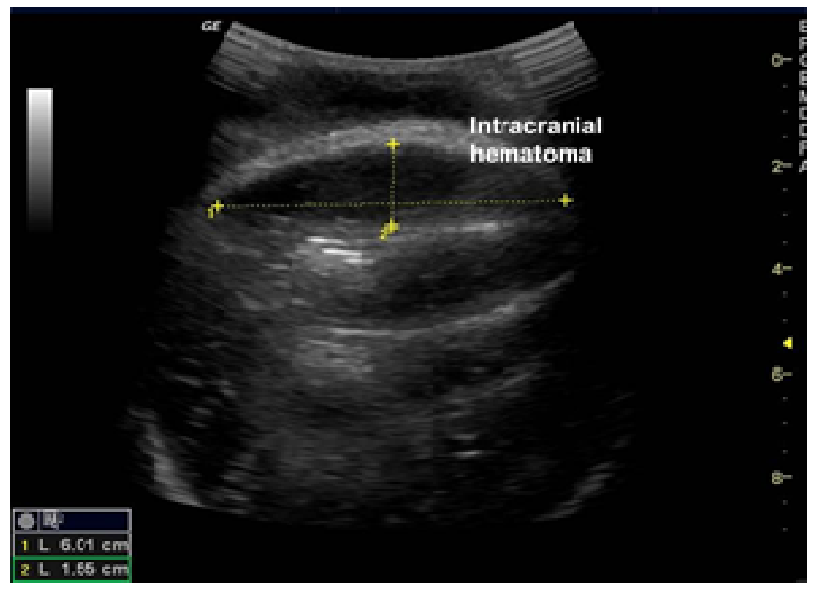

Figure 1. Image of ultrasound using 3, 5 - $7 \mathrm{MHz}$ convex probe. The intracranial hematoma is fully displayed, measuring $6.0 \times 1.5 \times 4.9 \mathrm{~cm}$.

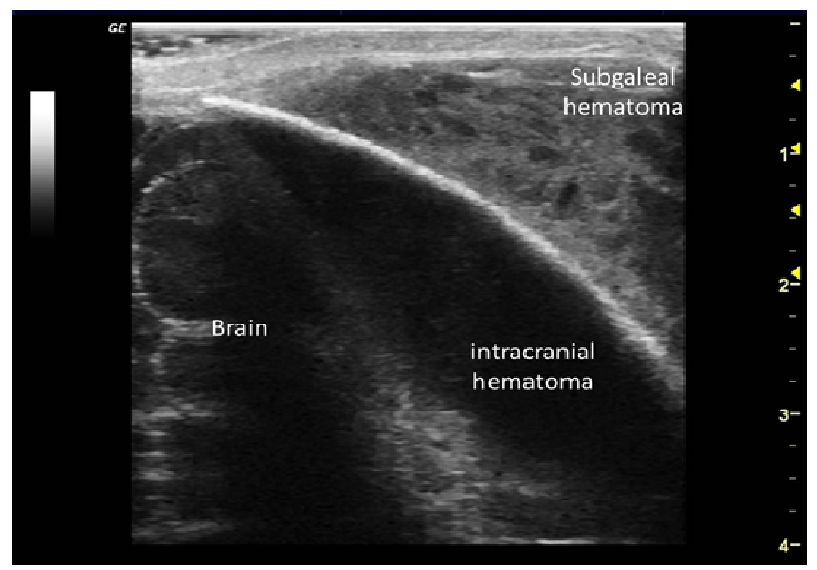

Figure 2. Image of ultrasound using $7-12 \mathrm{MHz}$ linear probe. Identifies clearly the subgaleal and intracranial hematomas.

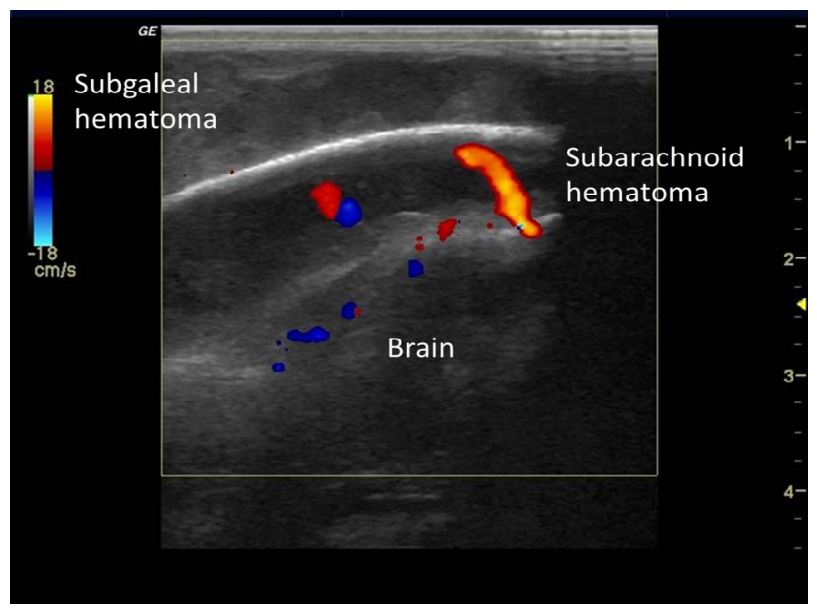

Figure 3. Image of ultrasound using $7-12 \mathrm{MHz}$ linear probe. Color Doppler showed blood vessels crossing the hematoma area (cortical vein sign), confirming the hemorrhage in subara-chnoid space.
We report a case of subarachnoid hemorrhage in an asymptomatic neonate presenting caput succedaneum after prolonged labor. US helped to identify an intracranial bleeding in the area corresponding to the subgaleal hematoma, which was gradually reduced until its complete resolution in the third week. The color Doppler was cardinal for the differential diagnosis between subdural and subarachnoid bleeding by showing the arachnoid vessels that crossed the internal area of the hematoma. Chen et al. reported for the first time the possibility of using color Doppler to differentiate between collections of subdural and subarachnoid space [2]. The identification of vessels crossing the liquid space characterizes subarachnoid hemorrhage, while in subdural hemorrhage the vessels found would be pressed against brain $[2,5]$. This has been described on computed tomography and magnetic resonance imaging (MRI) under the name of "cortical vein sign" [6,7]. Color Doppler US depiction of the "cortical vein sign" appears to be as effective as MRI in differentiating enlargement of the subarachnoid fluid space from subdural effusion $[2,5]$.

The advantages of US are that it is a non-invasive and easy-to-perform technique that does not require sedation like other imaging techniques (e.g., CT, MRI) [5]. Color Doppler is complementary to cranial grayscale US and it is a reliable technique for the differential diagnosis of intracranial extraaxial fluid collections.

\section{REFERENCES}

[1] C. B. Looney, J. K. Smith, L. H. Merck, H. M. Wolfe, N. C. Chescheir, R. M. Hamer and J. H. Gilmore, "Intracranial Hemorrhage in Asymptomatic Neonates: Prevalence on MR Images and Relationship to Obstetric and Neonatal Risk Factors," Radiology, Vol. 242, No. 2, 2007, pp. 535-541. doi:10.1148/radiol.2422060133

[2] C. Y. Chen, T. Y. Chou, R. A. Zimmerman, C. C. Lee, F. H. Chen and S. H. Faro, "Pericerebral Fluid Collection: Differentiation of Enlarged Subarachnoid Spaces from Subdural Collections with Color Doppler US," Radiology, Vol. 201, No. 1, 1996, pp. 389-392.

[3] L. H. Lowe and D. I. Bulas, "Transcranial Doppler Imaging in Children: Sickle Cell Screening and Beyond," Pediatric Radiology, Vol. 35, No. 1, 2005, pp. 54-65. doi:10.1007/s00247-004-1257-X

[4] A. Gover, A. Bader, M. Weinger-Abend, I. Chystiakov, E. Miller, E. Riskin, O. Hochwald, L. Beni-Adani, E. Tirosh and A. Kugelman, "Head Ultrasonograhy as a Screening Tool in Apparently Healthy Asymptomatic Term Neonates," The Israel Medical Association Journal, Vol. 13, No. 1, 2011, pp. 9-13.

[5] M. N. Zenger, S. Kabataş, S. Zenger and H. Cakmakçi, "The Value of Power Doppler Ultrasonography in the Differential Diagnosis of Intracranial Extraaxial Fluid Collections," Diagnostic and Interventional Radiology, 

Asymptomatic Full-Term Neonate: A Case Report

Vol. 13, No. 2, 2007, pp. 61-63.

[6] M. Morota, K. Sakamoto, K. Nishimura and K. Fujiwara, "Subarachnoid Fluid Collection in Infants Complicated by Subdural Hematoma," Child's Nervous System, Vol. 11, 1995, pp. 459-466. doi:10.1007/BF00334966
[7] N. Aoki, "Extracerebral Fluid Collections in Infancy: Role of Magnetic Resonance Imaging in Differentiation between Subdural Effusion and Subarachnoid Space Enlargement," Journal of Neurosurgery, Vol. 81, No. 1, 1994, pp. 20-23. doi:10.3171/jns. 1994.81.1.0020 